\title{
Optranet: a European project
}

\section{Marie Jeanjean}

Marie Jeanjean, "Optranet: a European project," Proc. SPIE 9663, Eighth International Topical Meeting on Education and Training in Optics and Photonics, 966317 (6 October 2003); doi: 10.1117/12.2207492

EDent: Eighth International Topical Meeting on Education and Training in SPIE. Optics and Photonics, 2003, Tucson, Arizona, United States 


\title{
Optranet : A European project
}

\author{
Marie Jeanjean \\ Opticsvalley, Palaiseau, France \\ mc.jeanjean@opticsvalley.org
}

\section{Diagnostics}

In a situation where curricula did not adjust at the required pace and many students are getting attracted out of science and technology, the shortage of skilled workers at the technician and engineer level is known to be a threat to development. In spite of a serious crisis in 2001, the trend of an increased presence of optical technologies remains unchanged and is bound to remain part of the landscape for decades. The level of investment required and the markets make Europe the best scale to plan for unified curricula and a global analysis of the human resources needs. There is no agreement on the definition of a trained optician, and European countries differ in the way they educate opticians, source of a lack of clarity and visibility which is detrimental to attracting good students and to the job market. Through its closely work with companies, OPTRANET will propose measures to enhance the adequacy and the visibility of the training offer.

The field of Optics and Photonics has evolved in the past 15 years into a professional domain with a need for highly skilled people and a growing importance of specific technologies. Specialised curricula at various levels of teaching, journals, learned societies and industrial activity clearly show that Optics/Photonics is a fairly well defined field with a significant growth rate.

For cultural and historical reasons, in particular related to language issues, European countries have developed independent systems for education in the field of $\mathrm{OP}$ as in many other fields, in relation between their higher education system and their industrial needs. Mutual knowledge and recognition between countries has been a marginal issue so far. At present, there is no agreement on the definition of what could be called a trained engineer, and European countries differ in the way they educate opticians: France has specific degrees, while Germany is developing specialized curricula and most other countries include optics as part of electrical engineering, physics, applied physics or optoelectronics. This creates a lack of clarity and visibility which is detrimental to attracting good students and to comply with the job market.

Because the situation we face is a period of such a fast evolution, it is hard to judge what jobs might be in demand 5 or 10 years ahead. Skills sets must be constantly upgraded to keep up with the fast pace of global markets. One of the reasons for focusing our program in strengthening the relationships between industries, research laboratories, universities and secondary schools is that it seems to be the best way to produce experts in technology transfer (the lack of skilled people in technology transfer has resulted in some weak industrial positions of Europe compared to the US or Japan, for a similar quality of research).

\section{Contribution to Training policies}

As mentioned in the European report on education and training in employment policies, "One of the challenges facing education and training systems is to ensure that the supply of education/training meets demand from both individuals and businesses."

As Optoelectronics is a quite new and worldwide industry with international competition for materials, technology and people, national answers for the above challenges are not significant. The level of investment required and the markets make Europe the most appropriate area to plan for more unified curricula and a global analysis of the human resources needs... 
Besides that, training policies ask for new schemes to adapt the content of education / training programme, and the whole European policy or initial training is only on a phase of definition.

By exchanging experience with the actors who implement such policies and procedures to develop a better matching between industrial reality and academic training, we can propose concrete actions towards schools and colleges that strongly attract pupils to science and that will permit teachers a better understanding of the skills to develop.

\section{Contribution to Industrial policy}

"The industrial policy of the Community aims at creating a knowledge-based society with enterprises operating on markets open to international competition. This policy is intended to foster innovation, sustainable development and the removal of obstacles to change. In addition, it seeks to promote Europe as a location for investment by companies, whatever their origin, and to enhance the competitiveness of European industry in an increasingly globalise context."

Our proposal will fulfil the two main aspects clearly mentioned above.

By an increase of high skilled people, we will remove some obstacles to innovation. Our action concerted with the IST current project will allow us to work with up-to-date information.

It will be easier for foreign companies in optics/photonics to find adequate Human resources in Europe. This will help for promotion of Europe on the worldwide level.

European added value of the consortium

Optranet project will reinforce the European community in optics-photonics and the exchange of experience and practices between the different members.

\section{The contents of the optranet project}

The two-year Optranet project is part of the European IST (Information Society Technologies) programme and involves five partners: Great Britain (Oxford Innovation), Germany (Optonet, JENA region), Sweden (ACREO, Stockholm region), Poland (Warsaw University) and France (Opticsvalley, Paris region). Opticsvalley is the project's European coordinator.

It began in April 2002 and will be closed in April 04.

As showed below, the main industrial actors as well as the most dynamic companies are in the close environment of these partners:

Opticsvalley (near Paris): Alcatel R\&D centre, Avanex (Nozay), Thales LCR (Orsay), Thalès optoelectronic R\&D centre (Guyancourt),SAGEM, Motorola R\&D centre (US),

OptoNet : Jenoptik AG, Fresnel Optics GmbH, Carl Zeiss Jena GmbH, Jena-Optronik GmbH, Leica

Microsystems Jena GmbH

Oxford region : Agilent technologies, JDS Uniphase (US), Marconi, Nortel Networks (US), booklam.

The European added value of the consortium is in their complementary skills and in the networks they manage.

These actors are well established in their own countries. They keep close contact with SMEs and large companies in their environment, which will ease the collection of relevant information about training needs.

The project's mission statement could be summarised as Highlighting and promoting the European training Offer in Optics and Photonics. 
The general program can be divided in 4 parts:

1/ Bridging the gap between industries, education and training in their environment

This section is a first trial to structure the different initiatives supporting optics and photonics in Europe.

Different initiatives have already structured the European landscape in this field.

In Germany, the Bundes Ministerium für Bildund und Forschung (BMBF) promoted a network of 7 regions.

In France, a network of 7 "poles" covering the most dynamic sectors (St Etienne, Marseille, Lannion, Bordeaux, Paris, Grenoble) has been built these last 2 years.

In the United Kingdom, a network brings together Scotland (represented by Scottish optoelectronics Association), Wales (Welsh optoelectronics forum), South-East England (SEPNET: a structure with excellence centres from Southampton, Oxford ...)

2/ Identifying new training needs by polling companies, research centres and corporate training centre

With the support of the network created to carry out the poll, OPTRANET will deliver the main elements available for the development of an Optics and photonics observatory dedicated to training needs for the next decade.

The objective is to carry out a survey of companies to find out how training matches the career opportunities in each country. The study will make recommendations to structure the optical syllabus.

OPTRANET will help define the required skills for a graduate at the technician or engineer level for a better adequacy with the industrial needs, and will validate it at the European level. This should increase professional mobility (for example, a national degree will be accepted or validated in any other European country) as well as student mobility (this European curriculum will enable students to continue their studies after moving in another country).

At the end of this project, OPTRANET will have delivered a complete overview of the European training offer in optics photonics and linked industries, as well as identified the needs of competencies required by the industry. This resource will be the cornerstone to elaborate basic European curricula for initial and continuous training. All these information will be delivered through the OPTRANET website that aims to become the European website for Training in Optics and Photonics.

Standardisation in training is another key element of our action. Through the use of European Credit Transfer System, we will enable higher education institutions to adapt these core European curricula into their own current and future courses.

Our objective is to drastically increase the number of higher education institutions involved in optics and photonics using ECTS system.

3/ Highlighting careers and challenges, to make people aware of these technologies. To increase the flow of future engineers and highly skilled manpower, OPTRANET will develop the interest of pupils and young people mainly in secondary schools using hands-on experience and mobile exhibitions.

Our "awareness' objectives" include the experimentation of optics toolkits with hundreds pupils, and the participation to 5 National major events (comparable "La fête de la science" in France).

4/ Promoting the ECTS (European Credit Transfer System) which measures and compares the courses taken by students and ensures that there are sufficient points of similarity between the establishments using it, so that the various countries of the European Community can cooperate.

Our plan should drastically increase the number of establishments that use it. 
To help students make the most out their study abroad and facilitate student mobility within Europe, the European Commission has developed a European Credit Transfer System (ECTS), which provides a way of measuring and comparing learning achievements, and transferring them from one institution to another. ECTS has been adopted by a variety of countries in Europe and is a method of standardising course content from Universities within Europe.

The European Commission promotes studies abroad as a means of improving the quality of academic cooperation and, therefore, bringing benefits to students and higher educational institutions. Studying abroad is perceived to be a particularly valuable experience for young people. It is a good way to learn about other countries, ideas, languages and cultures.

Students who plan to study abroad typically look for:

Study programmes which are relevant for their final degree

Full academic recognition that ensures that they will not waste time in completing their degree by studying abroad.

It is a credit accumulation system that has developed rapidly throughout Europe In the countries within Europe, students normally are granted 60 credits for a year (and 120 credits in the UK)

The number of ECTS credits is determined by the student workload. This includes lectures, laboratory work, private study, library time, coursework, continuous assessment and examinations.

At the moment a great deal of training centres do not use the system and European students are not well informed about it.

\section{The Optranet pedagogical kit}

An Optranet teaching kit has been manufactured in France by a French company which markets training materials (DMS/ DIDALAB).

Four copies of the kit have been released (three for France and one for Great Britain).

They are used in France: through the network of physics teachers, in the French optics clusters through the contacts those clusters maintain in the field of education at exhibitions, colleges and school open days and any fairs promoting scientific and technical education.

The teachers who use the teaching kit rely on quality equipment to explain the main aspects such as the components of light, the formation of an image and the propagation of light.

Young people will thus learn what a laser or optical fibre is and how they are used in everyday life. They can go further and learn about polarization. They can also understand the role of the glass and optical components used to manufacture instruments that use light.

Brochures are available to set up the equipment and conduct the experiments. The history of the optical field is introduced as well as applications fields. Slides can help teachers explain optical phenomena.

For the French version of the optranet kits, we have filmed a documentary called "Demain un métier dans l'optique" (6 minutes):"Tomorrow a job in optics" which explains the sector and the different technologies. We have underscored the training curricula and courses linked the engineering, technician and operator jobs. This film is distributed through opticsvalley and its network of the French optics clusters.

$>$ The "Spectrum Mobile" is a travelling exhibition in a small truck that visits colleges and high schools in England and in the European countries as France and Germany thanks to the optranet project.

It's an interactive way of demonstrating light and how it is used in everyday life: a demonstration of light and electricity following the electromagnetic spectrum in a $5.5 \mathrm{~m}$ mobile unit. It connects education and the national curriculum with the Optoelectronics industry in a stimulating and relevant manner by: 
Introducing the concepts of Optoelectronics

Demonstrating the use of photonics in our everyday lives by enabling pupils to find out how photonics based

communication systems work.

Modular interactive circuits are set up to explain principles and operation

Curriculum delivery units guide participants through displays and practical activities.

The Challenge section offers a variety of activities from building solar powered vehicles to controlling robots using programmable chips and infra-red communication

Website: www.formulaschools.com/electronics/spectrum.htm

$>$ The Cobrabid and Sensomed polish kits are also used in Poland to promote the optical field

The European website

Its address is www.optra.net

It was started in April 03.

The site's targets are:

Students who want to study optics in other countries.

Students who want to broaden their knowledge of the field.

Teachers in the optics field

The site aims at publicising the work done by the partners on the following subjects:

teaching and pedagogical kits

courses available and descriptions of the qualifications and degrees with an indication of how they match up in a table form

surveys of the companies and a summary of the conclusions with recommendations for any new courses ECTS and its promotion to campuses that do not use it

information in the form of news items on teaching optics and photonics: a new qualification, an exhibition, a conference 4 newsletter to be produced by the partners

The major components of the site are:

Training and ECTS

Pedagogical kits

Surveys

$>$ Training part:

Keeping in mind the fact that the difficulty in Europe lies in the absence of equivalent degrees, diplomas and qualifications commonly shared by all countries, we have detected qualifications which have been defined at four levels:

vocational training

advanced vocational training

Undergraduate

Graduate and postgraduate

These qualifications are mandatory to open up "job opportunities" as:

operators,

operators/technicians,

superior technicians,

Engineers.

Practically it's possible to find other qualifications in the different countries by using a search engine. 
We currently have included:

174 diplomas and degrees: 61 in

France

94 in Germany

5 in Poland

3 in Sweden

11 in UK

293 training centres:

212 in France

43 in Germany

19 in Poland

9 in Sweden

10 in UK

Survey part:

All the project partners carried out a survey of companies to find out how training matches the career opportunities in their own country by sending out a questionnaire.

We sent 630 questionnaires or conducted face to face interviews. We received 185 answers. We contacted more than 30 training centres in the optical field.

The results are on line.

Each country made recommendations to explore and implement.

\section{The ECTS (European Credit Transfert System)}

For the optranet website we have defined two targets:

the students

the training centres

For the students, the training centres that use already the system are listed. We are putting the list on line to keep informed the students about the possibilities of exchange.

For the second target (the training centres), we deliver on the website, information on the system, with documents which explain:

how to implement the system

who the ECTS representatives are

what forms should be filled

what is implied in terms of work and preparation

Some experiences will be described on the website.

Three meeting have to be organized to introduce the Methodology to the training centres, until completion of the project in France, United Kingdom and Germany.

\section{WORKSHOPS AND COMMUNICATION}

We have organized a first workshop with a roundtable in Oxford on April 2003, around the theme: » The results of the surveys". Industry was present. There was a general consensus that there was not enough emphasis placed on optics at the undergraduate level for technicians (for example). 
$>$ The second workshop will be held in Jena in Germany on November 2003. The theme will be: "Laser and technology: toward a vivid European cooperation in academic training"

Each project partner will attend with a training specialist centres from their country, to promote contacts between teachers and the campuses in Europe.

$>$ Communication about the training courses in the bio-photonics field is planned at the time of the OPTO trade fair in Paris on October 2003. An experts committee will be launched then.

It will suggest state of the art leads to implement contents and training courses at the technician and engineer levels in the bio-photonics field.

$>5$ national events for the dissemination of the optranet kits in France, England, and Poland are scheduled this year. For example, the "Fête de la Science" in France, organized each year in October, is a major event where children and their family, pupils and their teachers can participate and visit the laboratories or science campuses to increase awareness on technical and scientific phenomena.

\section{CONCLUSION}

By exchanging experience with actors who implement training policies in order to better match the industry needs and the academic training, Optranet proposes concrete actions which :

strongly attract pupils to science

will permit teachers to reach a better understanding of the skills to develop

Will contribute to highlight the European competencies in optics. 